\title{
Elastic properties and structure of alloys TiNi-TiFe prior martensitic transformations
}

\author{
S.A. Muslovi, ${ }^{1, \dagger}$ V.N. Khachin ${ }^{2}$, V.G. Pushin ${ }^{3}$, Yu.I. Chumlyakov ${ }^{2}$ \\ †muslov@mail.ru

\begin{abstract}
${ }^{1}$ A.I. Evdokimov Moscow State Medical Dental University, 20/1, Delegatskaya St., 127473 Moscow, Russia
${ }^{2}$ V.D. Kuznetsov Siberian Physico-Technical Institute, 1, Novosobornaya Sq., 634050 Tomsk, Russia

Ekaterinburg, Russia
\end{abstract} \\ ${ }^{3}$ Institute of physics of metals, Ural branch of the Russian Academy of Sciences, 18, S. Kovalevskaya str., 620137
}

Elastic properties of single crystals of TiNi-TiFe alloys stable to martensitic transformations (MT), undergo one B2-R and two B2-R-B19' MT are investigated by ultrasonic method of compound vibrator. Measurements were taken within the temperature interval of 77-873 K. In the alloys based on TiFe $\left(\mathrm{Ti}_{50} \mathrm{Fe}_{50}\right.$ and $\left.\mathrm{Ti}_{50} \mathrm{Ni}_{25} \mathrm{Fe}_{25}\right)$, which composition is far from alloys with martensitic transformation the elastic constant lattices $\mathrm{C}^{\prime}$ and $\mathrm{c}_{44}$ show a normal behavior at cooling $\left(\mathrm{dC}^{\prime} / \mathrm{dT}<0, \mathrm{dc} / \mathrm{dT}_{44}<0\right)$, and their values are rather high. The first evident signs of stability decrease in B2 structure of the studied alloys can be seen in the alloys with transient iron content. $\mathrm{Ti}_{50} \mathrm{Ni}_{35} \mathrm{Fe}_{15}$ is a normal temperature dependence $\mathrm{C}^{\prime}(\mathrm{T})$ and $\mathrm{c}_{44}(\mathrm{~T})$, which is gradually turning abnormal at a certain lower temperature. Finally in TiNi based alloys clear anomalies of the elastic properties are completed by B2- $\mathrm{R}$ transformation to $\mathrm{Ti}_{50} \mathrm{Ni}_{45} \mathrm{Fe}_{5}$ (at $185 \mathrm{~K}$ ) and transformation chains B2-R-B19' into $\mathrm{Ti}_{50} \mathrm{Ni}_{48} \mathrm{Fe}_{2}$ and $\mathrm{Ti}_{49} \mathrm{Ni}_{51}$ at a temperature lower than 240 и 285 K correspondently. Significant crystal lattice softening of TiNi-TiFe alloys prior MT is established. At the same time the elastic anisotropy approaches to the theoretically minimum value. XRD and transmission electron microscopy confirm that prior MT crystal lattice becomes unstable to the displacements of the atoms on the static type of plane waves.

Keywords: Pre-martensitic phenomena, single crystals, elastic constants.

\section{Introduction}

Specific mechanical properties of double and multicomponent B2 titanium compounds with Ni (figure 1), Fe, Co, Pd, Pt, $\mathrm{Au}, \mathrm{Cu}$ and other elements are well known and specified by martensitic transformations preceded by pre-transformation phenomena [1].

At the same time elastic properties of these compounds are not studied completely and elastic crystal lattices cij actually were not investigated at all, though these lattices directly reflect the character of interatomic binding and alloys

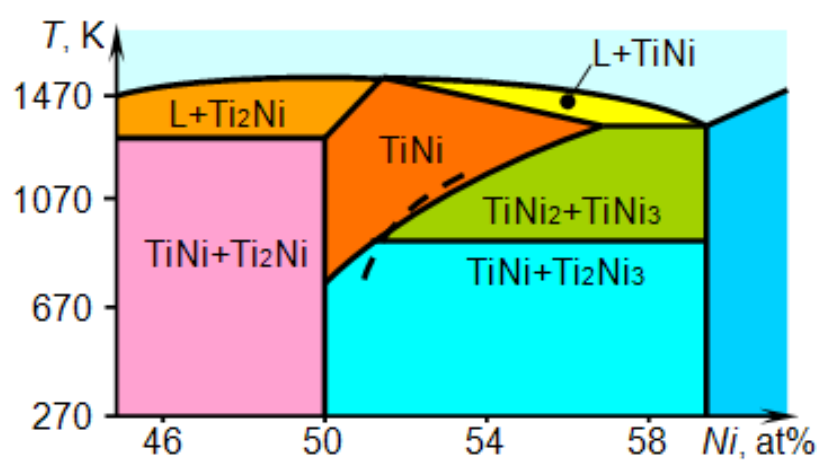

Fig. 1. Diagram of Ti-Ni system phase equilibrium. stability to pre-transformation and martensitic structures formation [2]. According to [3] the stability criteria to infinitesimal deformations for cubic lattices are as follows:

$$
\begin{aligned}
& c_{11}+2 c_{12}>0 \\
& c_{11}-c_{12}>0 \\
& c_{44}>0
\end{aligned}
$$

Accordingly a crystal loses its stability to sharing deformations providing $C^{\prime}=\frac{c_{11}-c_{12}}{2}=0$ or $c_{44}=0$.

Absence of investigations of the elastic constants in B2-compounds on titanium base for a long time had been connected with technical difficulties to get the single crystals of a sufficient size. The first results obtained [4] were not duly covered in literature.

This article describes the unique single crystals TiNi and $\mathrm{Ti}(\mathrm{Ni}, \mathrm{Fe})$ obtaining and studies of their elastic properties and structure in pre-transformation state.

\section{Materials and experimental techniques}

The alloys single crystals (figure 2 ) of volume about $10 \mathrm{~cm}^{3}$ and blocks misorientation not more than $1-1,5^{\circ}$ were 
obtained by the Bridgeman method in graphite crucible.

The single crystals $\mathrm{Ti}_{50} \mathrm{Ni}_{50-\mathrm{x}} \mathrm{Fe}_{\mathrm{x}}$ were grown in the laboratory of V. Kuznetsov SPhTI by S. Muslov for the first time in the world.

A single crystals composition and accordingly martensitic transformation temperatures differed a little bit from initial ones due to high chemical reactivity of titanium to carbon. The temperatures of transformation beginning $\mathrm{B} 2-\mathrm{R}\left(\mathrm{T}_{\mathrm{R}}\right)$ and R-B19' $\left(\mathrm{M}_{\mathrm{s}}\right)$ were determined by X-ray structural analysis and electrical resistance. The elastic properties were studied by jointed piezoelectric vibrator method [5].

Martensitic transformations (figure 3) and unique properties of shape memory and superelasticity connected with them specify particular research and practice value of this alloys system [6]. Single crystals composition $\mathrm{Ti}_{50} \mathrm{Ni}_{50-\mathrm{x}} \mathrm{Fe}_{\mathrm{x}}$ $(\mathrm{x}=50,25,15,10,5,2)$ and $\mathrm{TiNi}\left(\mathrm{Ti}_{49} \mathrm{Ni}_{51}\right)$ were chosen to study elastic properties of lattice B-2 which gradually loses its stability firstly to one B2-R, then to two B2-R-B19' martensitic transformations. At this $\mathrm{B} 2$ is a high-temperature phase with

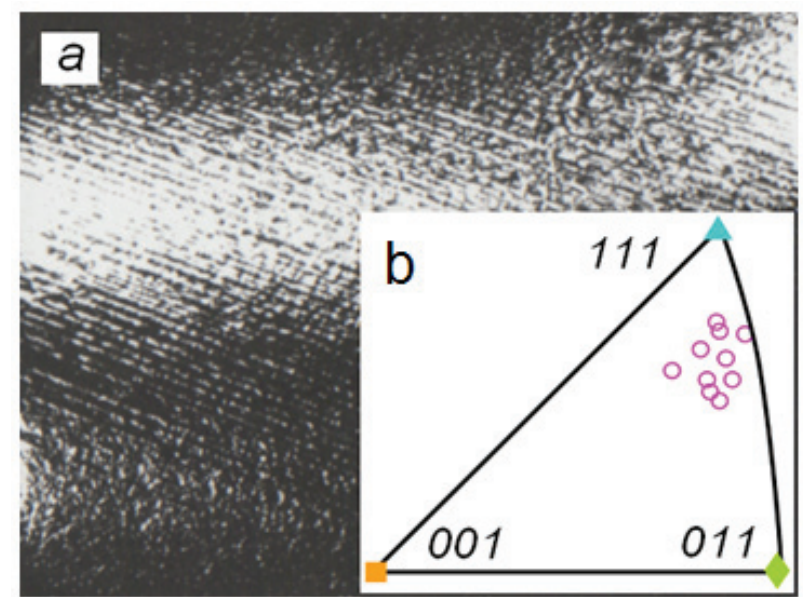

Fig. 2. Etching lines (a) and growing axis (b) of unique single crystals $\mathrm{TiNi}-\mathrm{TiFe}$, obtained in nitrogen atmosphere and used for the lattice elastic constants studies.

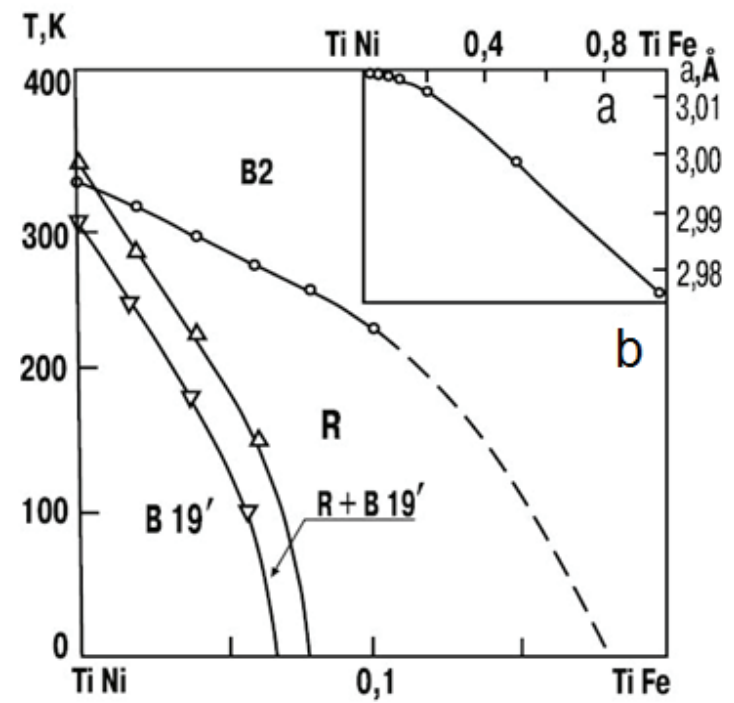

Fig. 3. Dependence of initial B2 lattice parameter on $\mathrm{Ti}_{50} \mathrm{Ni}_{50-\mathrm{x}} \mathrm{Fe}_{\mathrm{x}}(\mathrm{a})$ composition and martensitic transformations in TiNi-TiFe diagram (b). a long-range order of $\mathrm{CsCl}$ type, $\mathrm{R}$ and $\mathrm{B} 19$ ' are martensitic phases with rhombohedral and monoclinic structures correspondingly.

\section{Investigations results}

\section{Elastic properties}

Temperature dependences of the elastic constants $C^{\prime}=1 / 2\left(c_{11}-c_{12}\right)$ and $c_{44}$ were obtained for all alloys studied. These dependences with their linear combinations determine B2 lattice resistance to deformations in all basic crystal shift systems and elastic anisotropy coefficient is equal to $\mathrm{A}=\mathrm{c}_{44} / \mathrm{C}^{\prime}$. Measurements were taken within the temperature interval of $77-873 \mathrm{~K}$.

In the alloys based on TiFe $\left(\mathrm{Ti}_{50} \mathrm{Fe}_{50}\right.$ and $\left.\mathrm{Ti}_{50} \mathrm{Ni}_{25} \mathrm{Fe}_{25}\right)$, which composition is far from alloys with martensitic transformation the elastic constant lattices $C^{\prime}$ and $c_{44}$ show a normal behavior at cooling $\left(\mathrm{dC}^{\prime} / \mathrm{dT}<0, \mathrm{dc}_{44} / \mathrm{dT}<0\right)$, and
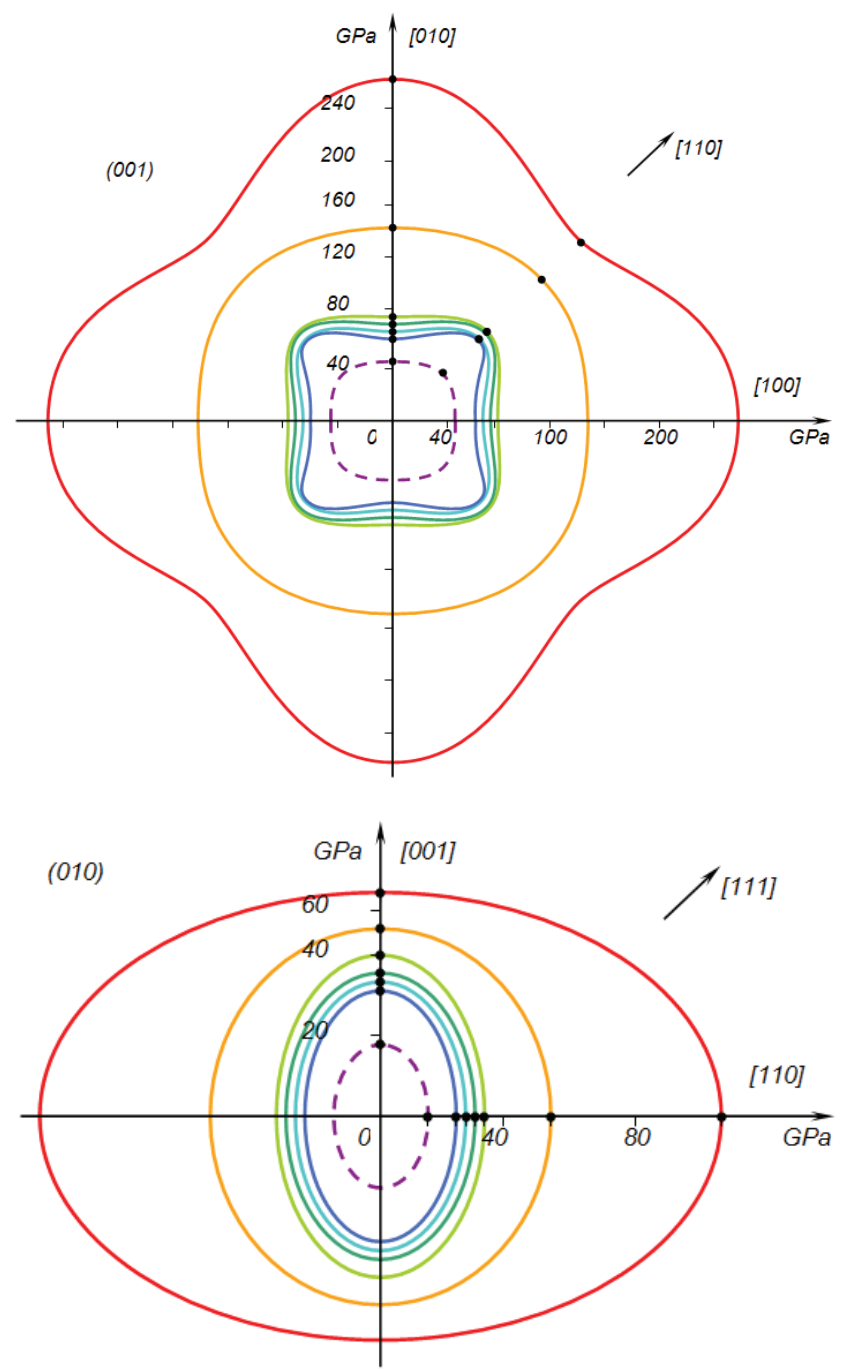

Fig. 4. Indication surfaces sections of Young modules (001) and alloys shift (010) before martensitic transformations ( $\mathrm{T}=285$ $\mathrm{K})$. Internal sections of modules surfaces correspond to binary compound TiNi $\left(\mathrm{Ti}_{49} \mathrm{Ni}_{51}\right)$. There are also sections of modules surfaces of three components alloys $\mathrm{Ti}_{50} \mathrm{Ni}_{50-\mathrm{x}} \mathrm{Fe}_{\mathrm{x}}, \mathrm{x}=2,5,10,15,25$, 50 correspondingly. 
their values are rather high. It is possible to mention only the following peculiarities of alloys elastic properties: crystals anisotropy $\mathrm{Ti}_{50} \mathrm{Fe}_{50}(A<1)$ unusual for metal systems and actually lattice elastic properties complete isotropy of intermetallic compound $\mathrm{Ti}_{50} \mathrm{Ni}_{25} \mathrm{Fe}_{25}(A \approx 1)$ caused by decrease of module $\mathrm{C}^{\prime}$.

The first evident signs of stability decrease in B2 structure of the studied alloys can be seen in the alloys with transient iron content. $\mathrm{Ti}_{50} \mathrm{Ni}_{35} \mathrm{Fe}_{15}$ is a normal temperature dependence $\mathrm{C}^{\prime}(\mathrm{T})$ and $\mathrm{c}_{44}(\mathrm{~T})$, which is gradually turning abnormal at a certain lower temperature.

As $C^{\prime}$ goes down more intensively than $c_{44}$ with nickel content growth, coefficient of elastic anisotropy in this alloy exceeds 1. In $\mathrm{Ti}_{50} \mathrm{Ni}_{40} \mathrm{Fe}_{10}$ the elastic constants "softening" can be seen throughout studied temperature interval (77$873 \mathrm{~K}$ ) and it grows in the low temperature interval. But this softening doesn't come to critical values and martensitic transformations are not realized.

Finally in TiNi based alloys clear anomalies of the elastic properties are completed by B2-R transformation to $\mathrm{Ti}_{50} \mathrm{Ni}_{45} \mathrm{Fe}_{5}$ (at $185 \mathrm{~K}$ ) and transformation chains B2-R-B19' into $\mathrm{Ti}_{50} \mathrm{Ni}_{48} \mathrm{Fe}_{2}$ and $\mathrm{Ti}_{49} \mathrm{Ni}_{51}$ at a temperature lower than 240 and $285 \mathrm{~K}$ correspondently.

Alloys lattice softening increases near structural transition, at this $\mathrm{c}_{44}$ changes more considerably than $\mathrm{C}^{\prime}$. As a result the initial $\mathrm{B} 2$ lattice comes to elastic isotropic and its deformation resistance becomes abnormally low in all basic crystal shift systems. The concentration dependence of alloys elastic properties also proves it (figure 4).

Abnormal behavior of TiNi-TiFe elastic properties and their evolution of compound composition changes allows to understand the nature of the structural phase transitions and the specific properties of titanium nickelide based alloys. Discovered B2 lattice softening at cooling directly proves its deformation stability decrease.

\section{Pre-transformation structures changes}

Theoretical calculations [3], analysis of images of electrons microdiffraction and X-rays diffraction (lauerograms) showed that in the conditions of simultaneous softening $\mathrm{C}^{\prime}$ and $\mathrm{c}_{44}$ up to critical values but zero B2 structure becomes unstable to the atomic displacements on the static type of plane waves $1 / 3<112><111>, \quad 1 / 3<110><110\rangle$, $1 / 2<110><110>$ and some other ones which initially form interim disproportionate shift structures and then final martensitic phases R- and B19 (figure 5)

Such elastic properties behavior is unusual even for the alloys with the martensitic transformations. Usually in premartensitic state only softening of shift module $C^{\prime}$ can be seen
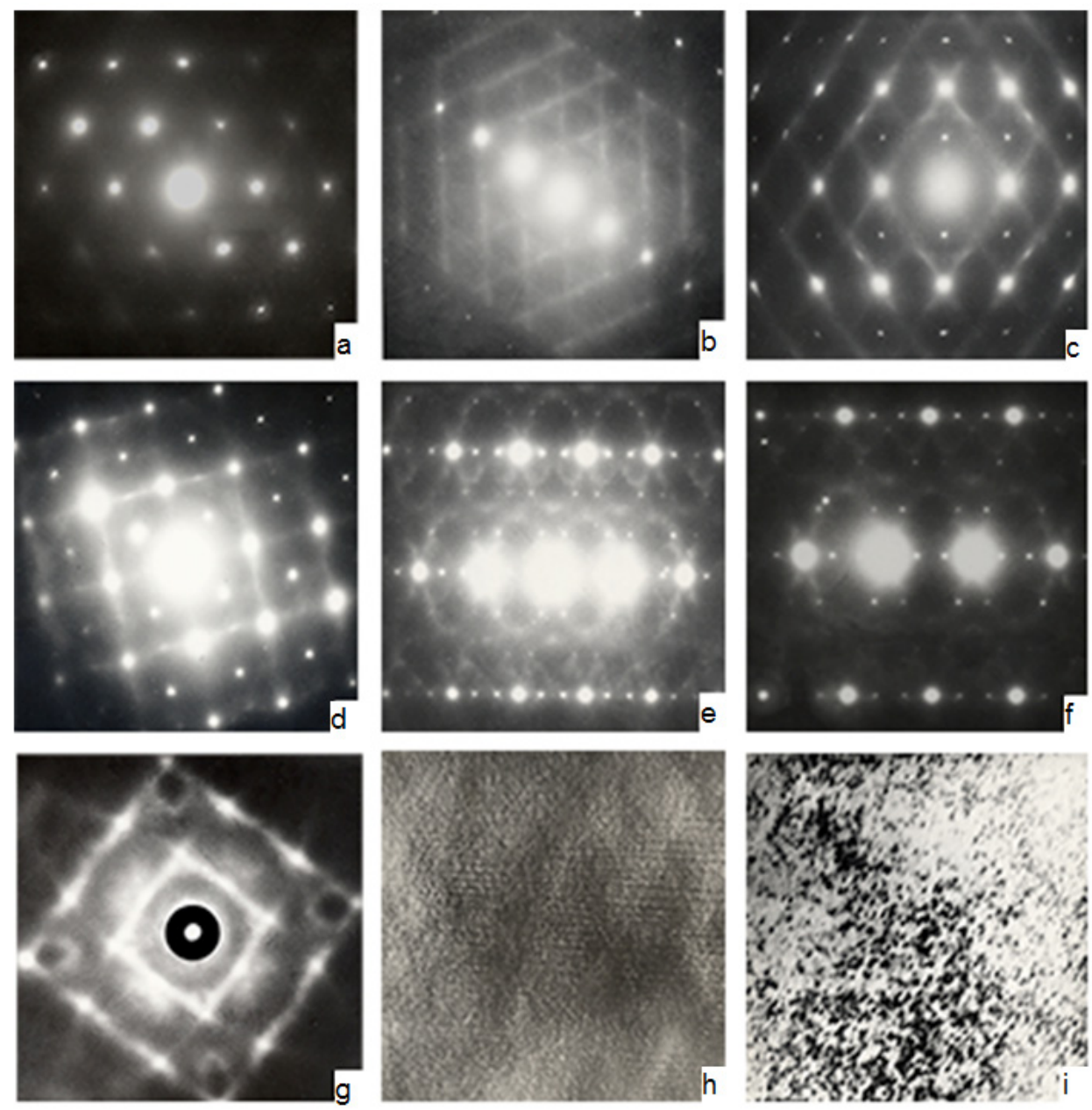

Fig. 5. Electron diffraction and radiographic effects of diffuse scattering: bands, diffusion stains and satellites near reflexes and between them (microdifractograms a-f, lauegram g) and tweed diffraction contrast (electron microscope images h-i). Results of structure research prove the presence of short-wave atoms displacements and pre-martensitic softening of alloys crystal lattice before transformations. 
as well as alloy elastic anisotropy growth up to abnormally big values $\mathrm{A}$ of the order $10-10^{2}$ [8]. Softening of the only shift system $\{110\}<110>$ resulted in revealing of one more channel of the martensitic transformation of B2-B19 type.

In TiNi based alloys together with martensitic transformation another B2-R is realized which needs additional atoms displacements in another system $\{112\}<111>$ and $\mathrm{c}_{44}$ softening.

Pre-martensitic softening of crystal lattice and its approach to isotropic one causes not only structural transformations but a high plasticity of TiNi and TiNi based alloys.

As only TiNi-TiFe alloys with iron content less than 5 at. $\%$ are subjected to plastic deformation, it appears that "switching " of usual dislocation sliding as well as structural transformations take place after softening of the lattice below the critical level.

\section{References}

1. A. S. Savvinov, V.P. Sivokha, V.N. Khachin. Metallofizika, 5 (4), 30 (1983) (in Russian) [А.С. Саввинов, В.П. Сивоха, В.Н. Хачин. Металлофизика, 5 (4), 30 (1983)].
2. V.G. Pushin, V.V. Kondratiev, V.N. Khachin. Izv. Vuzov. Fizika. 55 (1985). (in Russian) [В.Г. Пушин, В. В. Кондратьев, В.Н. Хачин. Изв. ВУЗов. Физика 55 (1985)].

3. V.V. Kondratiev. FMM, 41 (6), 1169 (1976) (in Russian) [В. В. Кондратьев. ФММ, 41 (6), 1169 (1976)].

4. V.N. Khachin, S.A. Muslov, V.G. Pushin, Yu. I. Chumlyakov. DAN SSSR 295 (3), 606 (1987) (in Russian) [В.Н. Хачин, С.А. Муслов, В.Г. Пушин, Ю. И. Чумляков. ДАН СССР 295 (3), 606 (1987)].

5. S. A. Muslov, V. N. Khachin. Izv. Vuzov. Fizika. 2105 (1987). (in Russian) [C.А. Муслов, В.Н. Хачин В.Н. Изв. ВУЗов. Физика. 2105 (1987)].

6. V.G. Pushin, V.N. Khachin, V.V. Savvinov. DAN SSSR, 277 (6) 1388 (1984) (in Russian) [В. Г. Пушин, В.Н. Хачин, А. С. Саввинов. ДАН СССР 277 (6) 1388 (1984)].

7. V.G. Pushin, V. N. Khachin, V. V. Kondratiev., S. A. Muslov, S. P. Pavlova, L. I. Yurchenko. FMM, 66 (2), 350 (1988 (in Russian) [В.Г. Пушин, В.Н. Хачин, В.В. Кондратьев, С. А. Муслов, С. П. Павлова, Л. И. Юрченко. ФММ, 66 (2), 350 (1988)].

8. H. Sakamoto, K. Shimizu, Trans. Jpn. Inst. Metals, 27, 601 (1986). 